\title{
Globe
}

Revue internationale d'études québécoises

\section{Manon Barbeau : Les Enfants de Refus Global. Office national du fillm, 1998, 74 min, 47 sec.}

\section{Isabelle Décarie}

Volume 2, numéro 1, 1999

URI : https://id.erudit.org/iderudit/1000124ar

DOI : https://doi.org/10.7202/1000124ar

Aller au sommaire du numéro

Éditeur(s)

Globe, Revue internationale d'études québécoises

ISSN

1481-5869 (imprimé)

1923-8231 (numérique)

Découvrir la revue

Citer ce compte rendu

Décarie, I. (1999). Compte rendu de [Manon Barbeau : Les Enfants de Refus

Global. Office national du film, 1998, $74 \mathrm{~min}, 47 \mathrm{sec}$.] Globe, 2(1), 141-144.

https://doi.org/10.7202/1000124ar d'utilisation que vous pouvez consulter en ligne.

https://apropos.erudit.org/fr/usagers/politique-dutilisation/ 


\section{RECENSIONS}

l'époque de la Révolution tranquille; et enfin, celle d'A. Gladischefski et M. G. Lieber, qui compare les politiques de féminisation des noms de métier en France, en Suisse, en Belgique et au Québec, et juge que le Québec est «à l'avant-garde des pays francophones», ceci parce que, à cet égard tout au moins, le poids de l'idéologie linguistique est moins grand ici qu'en France.

Michel Lacroix Université McGill

\section{Manon Barbeau \\ Les Enfants de Refus Global. \\ Office national du film, 1998, $74 \mathrm{~min}, 47 \mathrm{sec}$.}

Étrange film que celui-ci, auquel on ne peut rester insensible, partagé entre le documentaire et la mise en scène. Manon Barbeau, fille du peintre Marcel Barbeau, a tenté, dans cette œuvre intime, de recoller les morceaux d'un "casse-tête», de rapiécer sa mémoire de fillette pour se souvenir, mais surtout, pour offrir une identité à son frère François, schizophrène, qu'elle a retrouvé à l'occasion du tournage.

Sur un fond d'images religieuses entrecoupées d'un discours de Maurice Duplessis, le film s'ouvre sur la lecture d'un passage de Refus Global qui parut en 1948. Tiré à 400 exemplaires, ce manifeste avait eu l'effet d'une bombe dans un Québec pétri par la noirceur d'un catholicisme étouffant. "Place à la magie, place à l'amoun, clamaient alors les signataires dont faisaient partie, entre autres, Marcel Barbeau, Jean-Paul Riopelle, Madeleine Arbour, Marcelle Ferron, Maurice Perron et surtout, le «Maître», Paul-Émile Borduas. C'est cette brèche ouverte par un trop grand amour de la liberté que Manon Barbeau, séparée de ses parents et de son frère en bas âge, examine ici en se demandant quel retentissement le manifeste a pu avoir sur les familles démembrées de ses signataires après 1948. Elle 


\section{REVUE INTERNATIONALE D'ÉTUDES QUÉBÉCOISES}

demande en effet à Marcelle Ferron si le refus ne fut pas aussi celui des liens familiaux, une rupture qui aurait agi sur les couples : "Ça passe ou ça casse!', s'exclame alors Marcelle Ferron qui est allée vivre en France, après que son mari eut obtenu la garde de leurs enfants.

Ce film a divisé la critique à sa sortie : on approuvait le discours des enfants ou celui des parents. De manière singulière, il fut l'instigateur de débats sur l'éducation, sur les choix posés par les parents modernes. Manon Barbeau, dans un entretien à la radio, expliquait que sa voix n'avait pas été entendue, qu'elle avait fait ce film pour renouer avec les signataires et ouvrir le débat autour des valeurs du Québec moderne. Il n'en fut rien puisque la plupart des signataires refusèrent de voir le film et de poursuivre la discussion.

Tout se passe comme si Manon Barbeau refusait à son tour de voir que son film relève plutôt d'une seule signature, la sienne, qui sert sa seule mémoire. Cette quête est ouvertement celle d'une jeune femme qui écrit son passé et met en scène le récit de son enfance oubliée.

Lorsque la voix over de Barbeau nous mène à "la fille du Maître», Renée Borduas, elle espère enfin trouver une des clés qui va lui permettre de comprendre. Le cadrage se fait ici des plus intimes : le gros plan sur Renée invite à la confidence et le ton des deux femmes en est un de petites filles. Si Renée Borduas avoue, en riant, qu'enfant, elle faisait partie des "choses inutiles», malgré les interrogations lancinantes de Barbeau, elle ne fustige pas ses parents ni surtout son père, dont elle a vu la peinture s'éclairer après qu'il eût quitté le Québec et sa famille, "parce qu'il était plus libre», confie-telle. La première moitié du film est centrée sur un «récit du père» à travers la figure de Borduas, mais aussi à travers celle du père de Manon et de François. Filmé dans son atelier en France, en train de peindre, Marcel Barbeau raconte l'importance qu'a eue pour lui le Maître, celui qui l'a «mis au monde spirituellement». La cinéaste tente de faire avouer à son père qu'il a abandonné ses enfants (tout comme sa mère, Suzanne Meloche, l'a fait en quittant le foyer), ce qu'il ne peut faire: dans un échange étonnant, le père affirme ne pas vouloir gâcher sa vie parce que son fils est schizophrène. Un long 


\section{RECENSIONS}

silence suit ce dialogue, finalement interrompu par la voix du père qui annonce qu'on n'a plus qu'à attendre, à attendre que la peinture de son tableau sèche...

L'autre grande figure paternelle de ce documentaire est Jean-Paul Riopelle, dont ses filles, Sylvie et Yseult, parlent avec une grande réserve. La première (cadrée de manière suggestive avec sa propre fille) a vécu entre la France et le Québec et avoue ne pas savoir d'où elle est, ne pas avoir de racines. Yseult, qui travaille sur l'œuvre de son père au Québec, associe une question posée par la cinéaste à une lecture qu'elle vient de faire sur le génie et la folie, et s'accorde pour dire que les créateurs viennent tous de familles désunies. La séquence suivante montre un Riopelle désabusé, aigri, et très drôle : "J'aime les oiseaux moches'», dit-il en regardant le ciel, comme pour clore la conversation, exclamation qui, juxtaposée au discours retenu de ses filles, acquiert un sens singulier.

La lecture de la correspondance entre la mère de Manon (qu'elle n'a jamais revue et qui a refusé de la voir pour le film), son père et Borduas fait basculer le fil du récit vers la quête de la mère. La deuxième partie devient dès lors une véritable fiction de soi : en jouant au détective, la cinéaste tente de lire le sous-texte des lettres et interprète les phrases mystérieuses signées de la main de sa mère, qui écrit par exemple, qu'elle ne peut rendre visite à Borduas car elle doit rester à la maison avec les enfants. Deux scènes significatives émaillent la construction de ce récit en quête d'origines. La cinéaste fouille dans des boîtes avec Catherine Mousseau, la fille du peintre, et tente de trouver une photo de sa mère. Elle découvre alors la photo d'une silhouette féminine près d'une fenêtre, et dit : "C'est peut-être ma mère... On va dire que c'est elle qui me regarde jouer dehors». Le rire de Catherine Mousseau retentit non sans malaise, "peut-être», dit-elle. Cette scène révèle le cœur secret du film : une jeune femme qui ne fut jamais regardée par sa mère se reconstruit une identité de petite fille, rejoue le personnage de l'enfant qu'elle fut. Ce n'est pas un hasard si Barbeau a tourné, en 1975, un film précisément intitulé Comptines, fascinée par le monde de l'enfance et le jeu des fillettes... 


\section{REVUE INTERNATIONALE D'ÉTUDES QUÉBÉCOISES}

L'autre scène fondatrice de cette œuvre a lieu dans un musée dont l'exposition s'intitule «Les automatistes et Saint-Hilaire». Manon Barbeau y "découvre» un tableau de sa mère, en compagnie de Renée Borduas. Cette découverte/mise en scène donne lieu à une scène très forte où Manon pose un pose un doigt sur la toile rouge sang de sa mère en disant : "J'approche, je brûle». Au ralenti, elle glisse ensuite un doigt sur la signature de sa mère puis, cadrée de biais avec Renée, elle pleure. Voilà bien pourquoi ce film ne saurait en être un de réconciliation : tout ici vise la reconstitution d'une perte, la mise en scène d'une douleur fondatrice qui ne trouve pas d'écho chez les autres enfants. Sauf peut-être chez le fils de Borduas, Paul, retrouvé en République Dominicaine et qui raconte avoir envoyé à son père une sculpture pour lui dire que "c'était correct», que tout le monde comprenait ses choix, aussi douloureux soient-ils. Son père, poursuit-il, serait mort cinq jours plus tard après avoir reçu la sculpture. Paul avoue qu'il ne se sent pas coupable de la mort de son père, comme s'il pensait l'avoir tué avec son envoi.

Tuer le père, le Maître qui, plus âgé que les autres signataires, aurait dû, selon Barbeau, les protéger contre eux-mêmes, revient à poser la question de l'abandon. L'étrange sublimation d'une perte initiale émerge donc de cette histoire et relève d'un fantasme d'autoengendrement dont témoigne la construction narrative plus fictive que documentaire. Les Enfants de Refus global, en d'autres termes, est une auto-fiction lyrique et touchante (malgré une caméra manipulatrice) qui recompose un passé collectif sur le mode du privé.

Isabelle Décarie Université de Montréal 